\title{
Economic and Pre-Economic Impact of Academic Medicine Frankfurt Am Main, Germany
}

\author{
Armin Töpfer $^{1 *}$, Steffen Silbermann ${ }^{2}$ and Anne Maertins ${ }^{3}$
}

${ }^{1}$ Chairman of the Research Group Corporate Management and Marketing, Technische Universität Dresden, Helmholtzstr, Germany

${ }^{2}$ Project leader of the Research Group Corporate Management and Marketing, Holländische, Germany

${ }^{3}$ Project leader and research assistant of the Research Group Corporate Management and Marketing, Technische Universität Dresden, Germany

\begin{abstract}
The current intense political and public debate about the financing system for academic medicine in Germany lacks one major argument concerning the output of university hospitals and medical faculties. The following research project presents an economic discussion about the benefits of Academic Medicine Frankfurt am Main by determining the value-added, employment and tax effects for public authorities in addition to the pre-economic effects in 10 identified performance areas, with three core areas: teaching, patient care and research.
\end{abstract}

Keywords: Academic medicine; Economic impact, Pre-economic effects; Tax effect; Employment effect; Value- added effect

\section{One of the Most Significant Aspects is Missing in the Discussion about the Financing System of German Medical Universities}

University medical centers in Europe are faced with multiple challenges, such as rising costs in health care systems, dramatic cutbacks in public funding and growing bureaucratic procedures [1,2]. Some scientists even speak of the "decline of academic medicine in Europe," which lags behind that of the USA and is challenged by upcoming and expanding Indian and Chinese academic medicine [3,4]. Currently, 5.2 million people are employed in the German health care sector. Of these, $22 \%$ work in hospitals and 180,000 in university hospitals [5-8]. As an economic sector, the health care industry has a strong stabilizing effect on the German economy $[9,10]$. Today, this industry generates an annual turnover in health care spending of more than $€ 300$ billion, which is equivalent to $11.3 \%$ of the GDP and is expected to increase $[11,12]$. In contrast to their general economic significance stated above, German hospitals are in a tight financial situation. In 2012, every second hospital suffered financially [13]. This is also true for the 33 university hospitals, which expect to generate a cumulative loss of approximately $€ 133$ million in 2014 [14,15].

When systematizing the performance of medical universities, which generally encompass university hospitals and medical departments, three core areas can be identified: research, teaching and patient care. Influencing factors of performance are highly complex. A crucial success factor is the financial equipment that is now under consideration [16-21]. In general, there are four main sources of financial funding for medical universities: DRGs (Diagnosis-Related Groups) to cover current costs of patient care, which contribute the highest share of the university hospital budget, approximately $80 \%$ [22] investments in real estate and large medical equipment financed by the federal states [23] the federal states' contributions to research and teaching for medical departments; and special task-oriented grants for university hospitals, as well as external funding by public and private institutions $[24,25]$.

The answer to the question of which public area investments are profitable in terms of achieved financial as well as non-financial values is highly important to political decision-makers. In recent discussions about financial contributions to university hospitals and medical departments, one significant argument has been missing, namely, what are their benefits to the national economy and society? Previous discussions focused solely on the cost perspective of the state and tax payers. Consequently, the average cost per stationary case in hospitals is taken as one key indicator and functions as a standard of evaluation (2013: €4,152) [26]. The clearly quantifiable benefits of the (federal) state investments are often not considered in these financial debates. This is surprising as they are key arguments related to the outputoriented perspective justifying financial investments. In this article, the determination of these benefits is presented based on empirical results delivered by another research project also carried out in 2014 with Academic Medicine of Frankfurt am Main, Germany, under the leadership of the authors of this article.

\section{Initial Situation at Academic Medicine Frankfurt am Main}

The University Hospital Frankfurt am Main and the Medical Department of the Johann Wolfgang Goethe University Frankfurt form Academic Medicine Frankfurt am Main, comprising a total of 32 clinical and 20 research institutes. As a result of a successful appointment strategy of leading positions in research, the greater part of the institutions' resources is concentrated on the four research priorities of the Medical Department Frankfurt, which correspond to the clinical focus. These are cardiovascular medicine, neuroscience, oncology/immunology and translational drug discovery [27-29]. As a result, the Medical Department and its faculties have achieved a strong position on the national $[30,31]$ and international stage [32-34]. Despite relatively high investments in the infrastructure of Hessian universities, the financial contribution of the federal state of Hesse to the Medical Department for research and teaching amounted to $€ 26,243$ per student, which is far below the German average of $€ 36,715$ per student $[35,36]$.

*Corresponding author: Armin Töpfer, Chairman of the Research Group Corporate Management and Marketing, Technische Universität Dresden, Helmholtzstr. 1001062 Dresden/Germany, Tel: +49 351463 32187; Fax: +49 351463 35237; E-mail: armin.toepfer@tu-dresden.de

Received June 01, 2016; Accepted July 07, 2016; Published July 11, 2016

Citation: Töpfer A, Silbermann S, Maertins A (2016) Economic and Pre-Economic Impact of Academic Medicine Frankfurt Am Main, Germany. Health Econ Outcome Res Open Access 2: 118. doi: 10.4172/2471-268x/1000118

Copyright: $\odot 2016$ Töpfer A, et al. This is an open-access article distributed under the terms of the Creative Commons Attribution License, which permits unrestricted use, distribution, and reproduction in any medium, provided the original author and source are credited. 
The economic situation of University Hospital Frankfurt am Main is tense as well, as is the state of the building and equipment. While realizing a stable turnover in patient care during past years despite a competitive regional environment, in 2012 the hospital generated a deficit of $€ 5.8$ million caused by the launch of a vigorous optimization program [37]. Furthermore, the formerly solid financial situation of the Medical Department of the Goethe University Frankfurt is also seriously threatened. Although the allocations of the federal state remained at a relatively constant level, rising inflation as well as tariff increases led to a reduction of Hesse's financial contribution in real terms ('scissor problem'). Therefore, the question arises whether this calls for a stronger investment of the federal state of Hesse.

\section{Objectives and Methods}

To answer this question, this study was authorized to determine the economic and pre-economic effects of Academic Medicine Frankfurt am Main in terms of benefits for the city of Frankfurt am Main, the federal state of Hesse and the Federal Republic of Germany. The study goes beyond typical performance measures of medical universities, such as the number of treatments, research projects and graduates, by determining the economic impact of these institutions. To assess the economic relevance of Academic Medicine in Frankfurt am Main, three key economic indicators with high importance to the various local authorities were defined, namely tax revenue, employment rate and the value-added effect. Comparable indicators can be found in analyses for private economic sectors.

The study was divided into two time horizons: first, a retrospective analysis of the base year 2012; and second, a prospective analysis from 2014 until 2019. Hence, the first time period-the 'current state'provides the foundation for determining pre-economic effects as well as for calculating the three economic indicators. Based on these results, the future time period entails a scenario analysis demonstrating the indicators' development according to three assumed decision options introduced in the previously mentioned financial debate. Therefore, an elaborate input-output model formed the research basis of this study. The identified financial input of Academic Medicine Frankfurt am Main amounted to $€ 513.4$ million in 2012. The input comprises the Hessian financial contribution for research and teaching to the Medical Department, the revenues derived from patient treatment by the University Hospital, further financial support of Hesse, grants as well as financial assignments of third parties and other operating income. These financial resources are defined as enablers of Academic Medicine Frankfurt am Main's performance. Opening the 'black box' of this medical institution, 10 performance areas were then determined by means of in-depth interviews with members of the senior management in addition to already existing research results: The core areas of (1) patient care, (2) research and (3) teaching are facilitated by supporting processes in the areas of (4) education, advanced and further training, (5) procurement, (6) administration, (7) facility management and (8) event management, (9) cooperation/settlement and (10) other activities. Next, for each of these identified performance areas causeand-effect relationships in the output direction were analyzed to initially identify the payment and buying power flows. These figures were needed to determine aggregated paid taxes, the effects of induced or directly achieved employment rates and the value added. In addition to direct effects, for example, the employer's contribution to the wage, further induced effects were identified, such as the expenses of patients' relatives, hosted symposia or the expenses of emergency services.

In the second step, based on the overall cause-and-effect model, pre-economic effects were identified in each of the 10 performance areas. Pre-economic effects, e.g., research excellence and medical reputation, represent relevant factors expected to result in economic effects in the future; however, they cannot be reliably quantified in the present $[38,39]$. To validate the cause-and-effect model of Academic Medicine Frankfurt am Main, it was presented to, discussed with and finally approved by 30 experts (i.e., all members of the board of directors, heads of clinics and administrative units as well as managing directors of subsidiaries).

Four data sources were defined to facilitate the collection of complete data and information: (1) data directly available to the management of Academic Medicine Frankfurt am Main; (2) decentralized information requested of each individual organizational unit (the first standardized survey for data concerned the base year 2012, with a participation rate of $82 \%$; the second standardized survey for data and arguments concerned future development, with a response rate of $74 \%$ ); (3) additional information derived from 28 semi-structured in-depth interviews with 30 experts; and (4) further data from statistical offices and authorities, e.g. tax laws and official statistics of the health care industry. Overall, these four sources were needed to quantify the causeand-effect model which then yielded the three economic indicators tax revenue, employment rate and value-added effect for each of the defined time horizons.

These key economic indicators of Academic Medicine Frankfurt am Main were calculated in a computational model over 5 layers based on the cause-and-effect model. The underlying assumption is that Academic Medicine Frankfurt am Main induces effects in payment and buying power flows. Figuratively speaking a 'domino effect' in the financial network is initiated, e.g., employees of the medical institution make their livings based on their wages, which generates further tax effects. The 1st layer included all direct and indirect effects in the identified 10 performance areas of Academic Medicine Frankfurt am Main itself, its employees and its subsidiaries. The 2nd layer of the computational model included the suppliers of Academic Medicine Frankfurt am Main, of its subsidiaries and of further companies assigned by Hessian Building Construction Management. The 2nd and all subsequent layers encompassed natural and juristic persons introducing further payment flows that were pursued together down to the 5 th layer.

\section{Results}

In the following section, we present the results of the retrospective analysis for base year 2012. Based on the validated cause-and-effect model, pre-economic effects of Academic Medicine Frankfurt am Main as the preliminary stage of clearly quantifiable economic effects in future years were identified and analyzed, first in each performance area and, second, according to their level of influence on the respective local authority. The main pre-economic effects in the three core areas are outlined in Figure 1. However, these pre-economic effects cannot be separated from one another as they are in large part mutually dependent for achieving the excellence level of medical universities. In sum, this qualitative analysis based on in-depth interviews as well as intensive literature research (with the main purpose of validation and further exploring the subject) has two main objectives: The first is to reveal clearly the effects of a medical institution's mission in a manner that is easy to understand. Second, as mentioned before: Whenever possible, the identified pre-economic effects were quantified according to the three economic indicators based on the four previously mentioned data sources, e.g., the spending of an average German household based on available publications of the Federal Statistic Offices. The results are presented in the following section as a Mixed Methods Research Design. 


\begin{tabular}{|c|c|c|c|}
\hline \multirow[t]{2}{*}{ iExamples } & \multicolumn{3}{|c|}{$\begin{array}{c}\text { Academic Medicine Frankfurt am Main } \\
\text { (Medical Department and University Hospital) } \\
\text { Retrospective Analysis } 2012\end{array}$} \\
\hline & Patient Care & Research & Teaching \\
\hline $\begin{array}{l}\text { City } \\
\text { Frankfurt } \\
\text { am Main }\end{array}$ & $\begin{array}{l}\text { - Innovative and unique treatments } \\
\text { - Leading contact for difficult and } \\
\text { complex cases } \\
\text { - Part of primary and standard care } \\
\text { - Partner in emergency cases }\end{array}$ & $\begin{array}{l}5 \text { Collaborative Research Centers } \\
\text { (CRC) and } 2 \text { Transregio CRC from } \\
\text { the DFG } \\
\text { - Collaboration with local non- } \\
\text { universitary research institutes } \\
\text { - House of Pharma \& Healthcare } \\
\text { provides input for local } \\
\text { pharmaceutical industry }\end{array}$ & $\begin{array}{l}\text { Education of future physicians, } \\
\text { nurses and further health care } \\
\text { professionals } \\
\text { - Collaboration with teaching } \\
\text { hospitals } \\
\text { - Specialist training for physicians } \\
\text { from the Academic Medicine as } \\
\text { well as general practitioners }\end{array}$ \\
\hline $\begin{array}{l}\text { Federal } \\
\text { State of } \\
\text { Hesse }\end{array}$ & $\begin{array}{l}\text { - University Cancer Center Frankfurt } \\
\text { as the only top oncological center } \\
\text { from the German Cancer Aid in } \\
\text { Hessen } \\
\text { - Establishing the Hessian } \\
\text { Oncology Concept with other } \\
\text { partners }\end{array}$ & $\begin{array}{l}\text { Sucess in Hessian research } \\
\text { funding program LOEWE with the } \\
\text { objective of answering research } \\
\text { questions collaborativly and } \\
\text { practically }\end{array}$ & $\begin{array}{l}\text { - Collaboration in education with } \\
\text { the universities of Gießen and } \\
\text { Marburg in order to secure the } \\
\text { quality of teaching }\end{array}$ \\
\hline $\begin{array}{l}\text { Federal } \\
\text { Republic } \\
\text { of } \\
\text { Germany }\end{array}$ & $\begin{array}{l}\text { - Leading position in the national } \\
\text { program to establish networks for } \\
\text { patients with rare diseases } \\
\text { - Innovator in the program 'Patient } \\
\text { Blood Management' in order to } \\
\text { optimize the ussage of blood } \\
\text { banks }\end{array}$ & $\begin{array}{l}\text { Taking part in } 2 \text { of the } 6 \\
\text { nationwide research programs for } \\
\text { common diseases } \\
\text { - } 1 \text { ERC Starting Grant and } 2 \text { ERC } \\
\text { Advanced Grants } \\
\text { - Winners of national awards, such } \\
\text { as the Leibniz Price }\end{array}$ & $\begin{array}{l}\text { - Leading scientists are engaged as } \\
\text { experts in the nationwide exams } \\
\text { for medical students }\end{array}$ \\
\hline & \multicolumn{3}{|c|}{ Future economic effects } \\
\hline
\end{tabular}

Figure 1: Selection of pre-economic effects of the 3 core performance areas of Academic Medicine Frankfurt am Main for 2012.

The key economic parameter initially studied is the tax revenue generated by Academic Medicine Frankfurt am Main. It can be understood as a direct return on public investments. For this purpose, the collected tax payments of all major sources in the five-layer computational model were calculated for Hesse and its municipalities as well as the other authorities in Germany in relation to their point of origin. According to the German tax system, part of the revenue remains with the federal government, another part goes to the federal states and a certain proportion flows to the municipalities. In other words, the tax effect identified here can be described as direct 'payback' for each federal institution.

The finally calculated tax effect of Academic Medicine Frankfurt am Main for the year 2012 is depicted in Figure 2. For the federal state of Hesse, Academic Medicine Frankfurt am Main achieved a tax effect of $€ 52.8$ million in 2012 , which corresponds to $57 \%$ of the guaranteed financial contributions of Hesse. Adding the tax revenues generated by Academic Medicine Frankfurt am Main for the Hessian municipalities amounting to approximately $€ 17.6$ million, $76 \%$ of financial grants by the federal state of Hesse are directly returned via the tax benefit (€70.4 million). Altogether, Academic Medicine Frankfurt am Main induced tax revenues amounting to $€ 257.1$ million for the federal republic, the federal states and its municipalities, which corresponds to a multiplier of $279 \%$ measured against the financial contributions of the federal state of Hesse (a factor of 2.8). Pre-economic effects with social outcomes, such as the (faster) recreation of the labor force due to excellent medical treatment, are not considered in the calculation, which was generally carried out in a conservative manner based on real effects and probabilities. That is why the actual tax effect of Academic Medicine Frankfurt am Main is estimated to be much higher.

The results of the determined direct, indirect and peripheral effectuated employment rate of Academic Medicine Frankfurt am Main are also shown in Figure 2. In 2012, the average annual employment level at Academic Medicine Frankfurt am Main was 4,105 (full-time equivalent) employees at the University Hospital and the Department of Medicine, including employees financed by third-party funds, apprentices and employees of subsidiaries of the University Hospital. The calculation of the induced employment relationships was also performed based on the 5-layer computational model. The number of peripherally caused employment relationships (2nd through 5th layer of the computational model) was calculated by using details of the subsidiaries, scientific studies and branch figures available from the Federal Statistical Office. Figure 2 illustrates the leverage employment effect caused by the 4,105 employees of Academic Medicine Frankfurt am Main. As a result, one employee (full-time equivalent) of Academic Medicine Frankfurt am Main directly or indirectly induces 1.1 further jobs in Hesse and 2.4 jobs nationwide. Subsidiaries of the University Hospital Frankfurt am Main generate the biggest single share of created jobs in Hesse. Furthermore, companies that depend on Academic Medicine Frankfurt am Main were considered only if their economic operations were attributed considerably and extensively to Academic Medicine. Due to the insufficient level of documentation of dependencies, many dependent institutions were disregarded, 

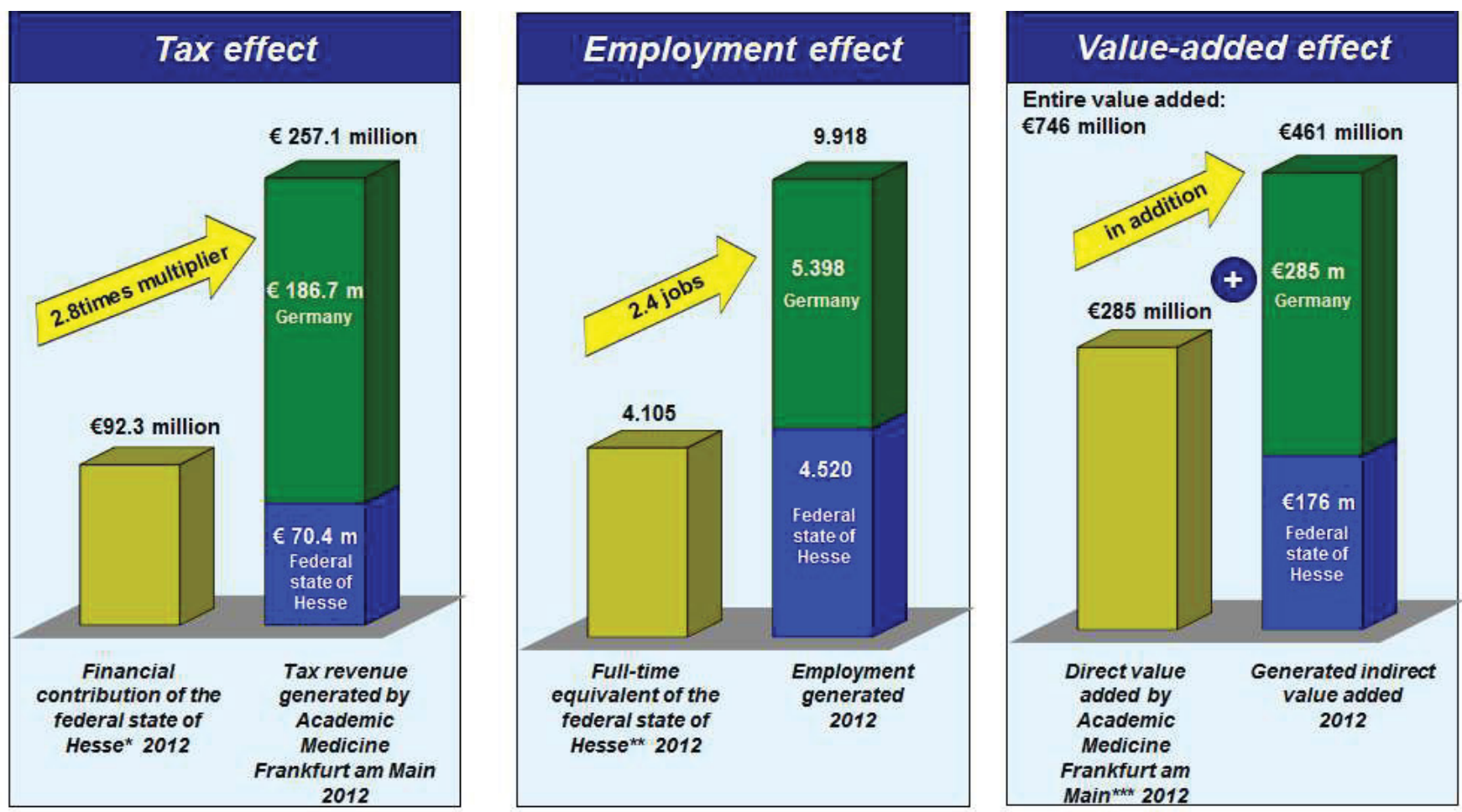

* Grant from the federal state of Hesse for research and teaching and for support tasks ( $€ 72.5$ million) + other grants and assignments of the federal state of Hesse ( $€ 19.8$ million)

" Average number of full-time equivalent in 2012 with the employment of the University Hospital and the Medical Department; including 556 full-time equivalent funded through external funds

*** Calculation of the net value excluding the depreciation expense

Figure 2: Economic effects of Academic Medicine Frankfurt am Main for 2012.

e.g., extended health care institutions cooperating on tumor therapy because of poorly equipped laboratories. Thus, it is presumed that the actual number of induced jobs is higher.

The value-added effect caused by Academic Medicine Frankfurt am Main is divided into three sections. (1) Direct value-added results from the performance in the three core areas. Key information for the calculation was taken from the profit and loss account of Academic Medicine Frankfurt am Main. (2) The indirect value added arises from the interaction between Academic Medicine Frankfurt am Main and further economic subjects on the 1st layer of the computational model. In addition to performance data of Academic Medicine Frankfurt am Main, such as the number of treated patients, the number of held symposia and the number of enrolled students, the calculation was also based on the data of the statistical offices. With the help of this collected data, questions of quantification, such as the spending of a single participant during a convention, can be answered and subsequently determined in Euro. (3) The peripheral value-added effect occurs through the demand for goods and services on the 2 nd through 5 th layer of the computational model. According to the definition of net value added by the German Federal Statistical Office, inputs are subtracted from the market price (excluding value-added tax). As shown in Figure 2, Academic Medicine Frankfurt am Main creates a value added in Hesse of approximately $€ 461$ million, which includes the direct value added of $€ 285$ million as well as the induced value added of $€ 176$ million for the federalstate of Hesse. Altogether, the value added in Germany amounts to $€ 746$ million, which corresponds to 2.6 times the direct value added. The identified net surplus value serves as payment for the utilized production factors and is disbursed as wages.
In the following, the results of the prospective scenario analysis of the economic effects for the future period 2014-2019 are briefly presented. The scenario analysis was carried out to assess the development of Academic Medicine Frankfurt am Main with the help of three scenarios, each of which is a general description of a consistent set of factors defining an alternative set of future business conditions [40]. Approved by the board of directors, each scenario consists of a variation of three main factors strongly affecting future economic development: (1) financial support from the federal state of Hesse for research and teaching efforts of the Medical Department, (2) the hypothetical nationwide implementation of a system grant for university hospitals justified by their outstanding role in the German health care system and (3) the realization of the 2 nd construction phase concerning a main building for medical treatment and research activities. Each scenario is depicted in Figure 3.

All heads of institutions were asked about their assessment of future developments regarding their own department, both in terms of qualitative and quantitative factors (see part 3, related to the second standardized survey). Concerning the latter, the heads needed to assess the development of their organizations relative to key parameters including number of employees, number of patients treated stationary and ambulatory, as well as the amount of third-party funds for the year 2015 and 2019 according to the three scenarios. After receiving the questionnaire, these parameters were validated by the surveyors and, where necessary, the head was contacted for further explanation. All collected data were incorporated into the extrapolated computational model for the period 2014-2019 with an assumed inflation rate of $2 \%$ 
Citation: Töpfer A, Silbermann S, Maertins A (2016) Economic and Pre-Economic Impact of Academic Medicine Frankfurt Am Main, Germany. Health Econ Outcome Res Open Access 2: 118. doi: 10.4172/2471-268x/1000118

\begin{tabular}{|c|c|c|c|}
\hline \multirow[t]{2}{*}{$\begin{array}{l}3 \text { influencing } \\
\text { factors }\end{array}$} & \multicolumn{3}{|c|}{3 scenarios depicting possible future states } \\
\hline & $\begin{array}{l}\text { Basic Scenario } \\
\text { (scenario 1) }\end{array}$ & $\begin{array}{l}\text { Positive Scenario } \\
\text { (scenario 2) }\end{array}$ & $\begin{array}{l}\text { Negative Scenario } \\
\text { (scenario } 3 \text { ) }\end{array}$ \\
\hline $\begin{array}{l}1 \text { Finanical } \\
\text { contribution for } \\
\text { teachingand } \\
\text { research }\end{array}$ & $\begin{array}{l}\text { Finanical contribution of } \\
\text { the federal state of Hesse } \\
\text { remains nominally the } \\
\text { same, leading to a real } \\
\text { reduction of }-2.4 \% \text { p.a. }\end{array}$ & $\begin{array}{l}\text { - Adjusting the financial } \\
\text { contribution to the German } \\
\text { average over all federal } \\
\text { states, leading to an } \\
\text { increase of } € 30 \text { million p.a. }\end{array}$ & $\begin{array}{l}\text { Reduction of the financial } \\
\text { contribution of about } € 1 \\
\text { million starting from } 2016 \\
\text { 2014: } €-0.5 \text { million } \\
\text { 2015: } €-0.75 \text { million }\end{array}$ \\
\hline $\begin{array}{l}\text { System } \\
\text { grant for the } \\
\text { university } \\
\text { hospital }\end{array}$ & No system grant & $\begin{array}{l}\text { - From } 2017 \text { additional } \\
\text { system grant of } € 30 \text { million } \\
\text { p.a. for the university } \\
\text { hospitalin order to make } \\
\text { necessary investments }\end{array}$ & - No system grant \\
\hline $\begin{array}{c}\text { Completion } \\
\text { of the } 2 \text { nd } \\
\text { construction } \\
\text { phase }\end{array}$ & $\begin{array}{l}\text { Completionand thus final } \\
\text { move-in in } 2017\end{array}$ & $\begin{array}{l}\text { - Completionand thus final } \\
\text { move-in in } 2017\end{array}$ & $\begin{array}{l}\text { - Delayed completion of the } \\
\text { main building in } 2019 \text { (after } \\
\text { the defined time horizon of } \\
\text { the scenario analysis) }\end{array}$ \\
\hline
\end{tabular}

Figure 3: Overview of the 3 defined scenarios for Academic Medicine Frankfurt am Main

and an average tariff increase of $2.5 \%$ (resulting in a total reduction of $2.4 \%$ p.a.). The nationwide induced development of the three key indicators was predicted on this basis (Figure 4). The effects for 2013 were also calculated as no actual values were available in time.

In Figure 4, a corridor is depicted that spans the Positive Scenario (upper line) and the Negative Scenario (lower line) for each economic key indicator. The results of the Basic Scenario lie between the other two scenarios. The actual figures from the retrospective analysis (20082012) indicate continuous growth. Both the induced value added and the achieved tax revenue increased $>5 \%$ p.a., which is above the inflation rate. This is also the case for the induced employment effect, but with an average annual growth of approximately $3 \%$. Concerning the forecasting horizon, future growth can only be realized in the Positive Scenario. A decrease for every key indicator is visible for the Negative Scenario. The decline between 2017 and 2018 in all scenarios can be explained by the cessation of Hesse's construction investments (Figure 3). The greatest disparity between the Positive and the Negative Scenario is predicted in the nationwide induced-employment effect (excluding the direct employment of Academic Medicine Frankfurt am Main), with a decrease between 2012 and 2019 of $-6 \%$ in the Negative Scenario compared with an increase of $13 \%$ in the Positive Scenario. Similarly, the nationwide induced value added is expected to drop by approximately $-3 \%$ in the Negative Scenario. However, in the Positive Scenario, effects of the inflation rate can be compensated for by an annual growth of approximately $2 \%$. This is also the case for the nationwide induced tax effect, which increases by $2.5 \%$ p.a. in the Positive Scenario and remains relatively constant in the Negative Scenario. In summary, the Negative Scenario suggests a decrease of the economic ability of Academic Medicine Frankfurt am Main in the future, whereas the key assumptions of the Positive Scenario indicate moderate organic growth.

\section{Discussion}

The intense political discussion concerning the financing system of university clinics and medical departments in Germany has gained a new argument in determining the economic output of medical universities by means of the key indicators tax, employment and valueadded effect (Figure 2). Representing the significance of the medical university in the regional and national contexts, these key indicators are of interest and importance to financial funding institutions, which must balance different investment alternatives. The importance of the results is raised specifically in the context of the predominantly intangible results of research, teaching and patient care, which are in most cases not visible at first glance (Figure 1). Regarding the presented effects for Academic Medicine Frankfurt am Main, two main issues must be considered: First, a series of pre-economic effects could not be included in the computational model due to a lack of valid data and assumptions. Second, this study is not intended to identify opportunities for rationalization as would be the case, for example, in a feasibility study. Additionally, when looking at the calculated effects, one might initially arrive at the interpretation that a reduction of state financial support improves each multiplier in the short run. However, when considering the medium term, a reduction of financial support leads to an over- proportional decrease of performance and thus of the induced economic benefits for the federal institutions [41]. This reduction is also indicated by the scenario analyses' results (Figure 4). 
Citation: Töpfer A, Silbermann S, Maertins A (2016) Economic and Pre-Economic Impact of Academic Medicine Frankfurt Am Main, Germany. Health Econ Outcome Res Open Access 2: 118. doi: 10.4172/2471-268x/1000118

Page 6 of 7

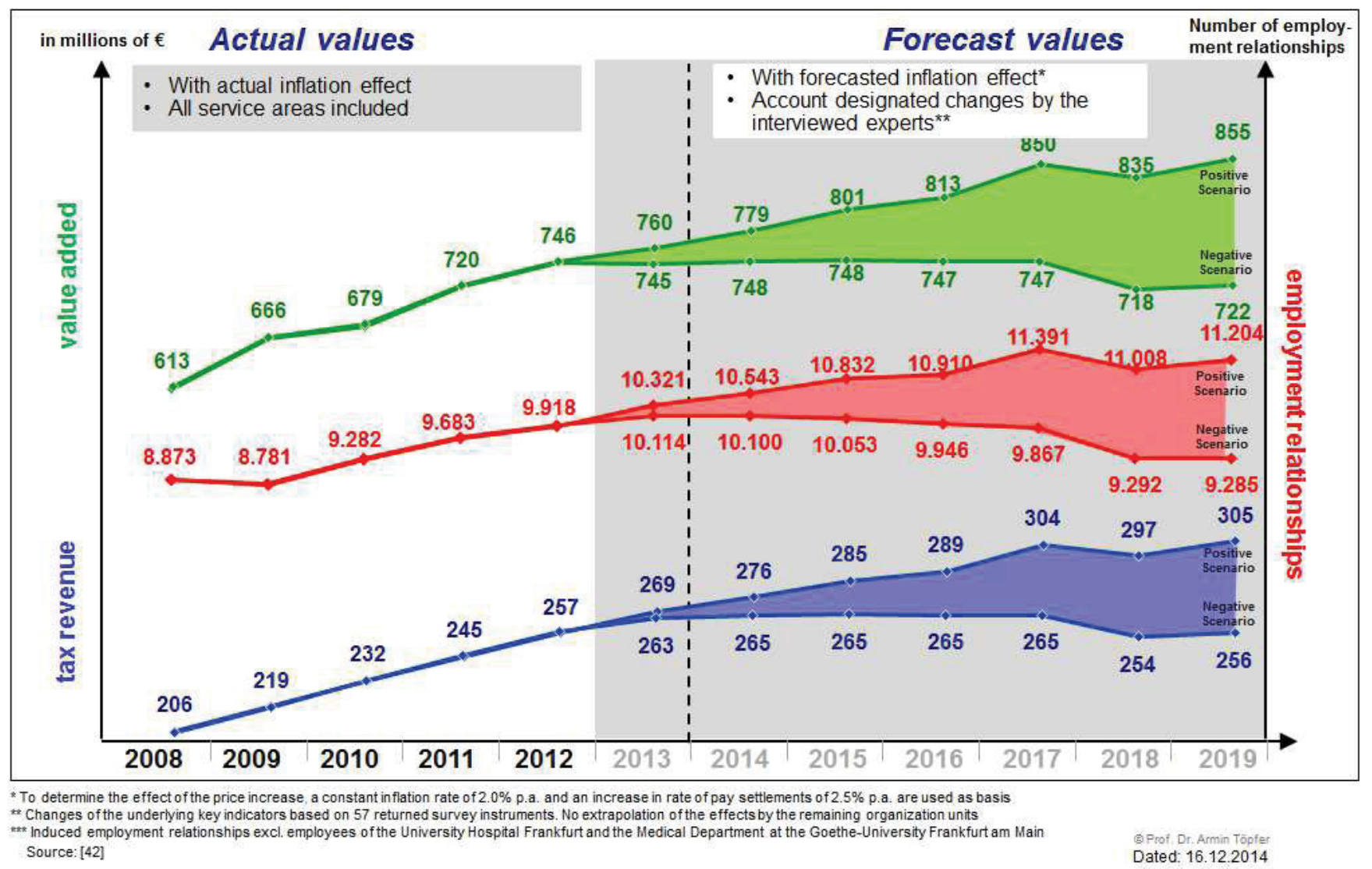

Figure 4: Development of the tax, the value added and the employment effect during the scenario horizon 2014-2019.

Providing a different perspective of Academic Medicine Frankfurt am Main as an important driver of the local economy, the politicians' mindset is reflected in the presented opinion. The core results of this study were sent to the Hessian Prime Minister, all members of the Hessian Parliament and leading political decision-makers in the corresponding ministries, as well as to all heads of clinics and research institutes by the board of directors of Academic Medicine Frankfurt am Main [42]. In addition, the results were presented to the public in a press conference. Adding a distributed press release and further information [43], all of these activities contribute to a more positive perception of Academic Medicine Frankfurt am Main [44-46]. Concrete results of the initiated political debate are currently pending. To provide some perspective, the experiences of our Research Group Corporate Management and Marketing at Technische Universität Dresden with comparable studies for other medical universities in Germany are briefly outlined. Findings for the University Medicine Heidelberg were introduced in the discussions about the financial contribution of Baden-Württemberg, which are documented in the form of publically available protocols $[47,48]$. For the University Medicine Dresden, the study's results of pre-economic and economic effects were a significant argument to avoid a further reduction of the financial contributions of the federal state of Saxony to the Medical Department. Furthermore, access to political decision-makers was facilitated [49]. Additionally, the University Medicine Göttingen presented the results of the three key indicators to the Prime Minister of Niedersachsen and to the press, resulting in newspaper headlines such as 'University Medicine is an engine for the local economy' [50].

\section{Conclusion}

Given its high capacity for innovation, Academic Medicine Frankfurt am Main has a strong potential for catching up with the nation's leading group of medical universities in Germany with international acclaim. Therefore, further efforts as well as investments of all actors are necessary. Academic Medicine Frankfurt am Main with an employment of 4,105 (full-time equivalent) has a relatively high impact on the Hessian economy: The medical institution generated $€ 70.4$ million in tax revenue, induced 4,520 additional jobs and created $€ 461$ million value added for the federal state of Hesse and its municipalities in the year 2012. In connection with the results of the scenario analysis, a new perspective of economic evaluation is brought to the political debate. This new building block in the argumentation about the financing system of medical universities in Germany can also be applied to other countries, showing that the economic benefits of medical universities are of value both on a regional and national level.

\section{Acknowledgment}

The authors want to thank Mr. Sebastian Langer, M.Sc. for the preparatory legwork for this paper.

\section{Highlights}

- Specifies output-oriented economic and pre-economic effects of a German medical institution.

- Calculates the tax, value-added and employment effects of Academic Medicine Frankfurt am Main.

- Determines the economic output of the University Hospital and Medical Department of the Goethe University in relation to the city Frankfurt am 
Citation: Töpfer A, Silbermann S, Maertins A (2016) Economic and Pre-Economic Impact of Academic Medicine Frankfurt Am Main, Germany. Health Econ Outcome Res Open Access 2: 118. doi: 10.4172/2471-268x/1000118

Main, the federal state of Hesse and its municipalities, and the Federal Republic of Germany.

\section{References}

1. AMICE International Network Office (2014) Introducing an amicable network of Academical Medical Centers in Europe.

2. Bräuniger D, Rakau O (2014) Health care industry in the ascendant. Deutsche Bank Research 2010

3. Sheridan DJ (2004) Reversing the decline of academic medicine in Europe. The Lancet 363: pp863.

4. Tugwell $P(2006)$ The campaign to revitalize academic medicine kicks off. The Lancet 367: 1698-701.

5. Federal Ministry of Economics and Technology Germany (2010) Innovation and growth-The German health care branch on the way to a leading branch. Second health care conference on October 4th 2010 in Berlin.

6. http://www.bmg.bund.de/gesundheitssystem/gesundheitswirtschaft/ gesundheitswirtschaft-als-jobmotor.html.

7. Bräuniger D, Stobbe A (2012) Health care industry: Further potential to go upward. Deutsche Bank Research.

8. Albrecht MD, Kroemer HK, Strehl R (2013) Financing of the university medicineAt the breaking point. Deutsches Ärzteblatt 110: 65-68.

9. Federal Ministry of Health Germany (2013) Data of health care.

10. Federation of German Industry (2013) The health care industry-A stable growth factor for the future of Germany. Strategic program of the committee of the Federation of the German Industry for health care.

11. Federal Ministry of Health Germany (2014) Meaning of the Health Care Branch.

12. Federal Government Germany (2010) Health care in the focus. Journal for Economics and Finances 88: 6.

13. Blum K, Löffert S, Offermanns M, Steffen P (2013) Hospital barometer survey 2013. Deutsches Krankenhausinstitut.

14. Verband der Universitätsklinika Deutschland (2014) Letter to the politics.

15. Verband der Universitätsklinika Deutschland (2014) Annual results of university hospitals massively collapsed.

16. Montgomery FU, Scriba PC, Kroemer HK (2013) Statement The future of the German University Medicine- Crucial facts for a sustainable development. Deutsches Ärzteblatt 110: A337-350.

17. Richter Kuhlmann E (2014) Collegiate medicine: separate way university hospitals. Deutsche Ärzteblatt 111: A429-30.

18. Burchard AA (2014) billion Euro for German university hospitals-deficits in the university medicine Tagesspiegel.

19. Flintrop J (2013) It is a bit over, is that ok. Deutsches Ärzteblatt 110: A536.

20. Finetti M, Schilden S, Kling Mathey C (2014) Do not compromise the future of the scientific system

21. Commission of experts research and innovation (2014) Report about research, innovation and technological capability of Germany Berlin 2014.

22. Amann I, Heyder R, StrehI R (2009) Investment and investment lag as risk factors for the university medicine. Bundesgesundheitsblatt-GesundheitsforschungGesundheitsschutz 8: 811-820.

23. Federal Ministry of Health Germany (2014) Fees of stationary and partly stationary hospital services.

24. German Medical Association and National Association of Statutory Health Insurance Physicians (2013) Statement Future of the German university medicine-critical factors for a sustainable development. Deutsches Ärzteblat 110: A337-350.

25. http://www.uniklinika.de/media/file/5440.14-07-10_PM_Anlage_Gutachten Mengenentwicklung_Aussagen_Uniklinika.pdf

26. Federal Statistical Office Germany (2014) Stationary expenses 2013 increased up to 78 bn euro.

27. Goethe University (2014) Research priorities at the faculty of medicine.
28. Goethe University (2011) Development plan of the Goethe University 2011.

29. Board of Directors University Hospital Frankfurt am Main (2012) Annual Report 2012. Frankfurt 2013.

30. University Hospital Frankfurt am Main (2012) Hessian's best physicians work at the university and medical faculty of the Goethe University.

31. Deutsche Forschungsgemeinschaft (2012) Funding atlas 2012 Bonn 2012.

32. ShanghaiRanking Consultancy (2013) Academic Ranking of World Universities in Clinical Medicine and Pharmacy.

33. TSL Education Ltd (2013) Top 100 universities for Clinical, Pre-clinical and Health 2013-14.

34. QS Quacquarelli Symonds Limited (2013) QS World University Rankings by Subject 2013-Medicine.

35. University Hospital Frankfurt am Main (2014) Consumptive expenses of the responsible ministeries for the Academic Medicine Frankfurt.

36. Deutsche Hochschulmedizin (2011) Financial contributions of the federal states 2011.

37. Verband der Universitätsklinika Deutschland (2014) Current financial situation of the German university medicine.

38. Töpfer A, Silbermann S, Maertins A (2011) Economical and non-economica effects of a medical facility. Zeitschrift für Evidenz, Fortbildung und Qualität im Gesundheitswesen 105: 701-707.

39. Töpfer A, Silbermann S, Maertins A (2014) Hospital are economic driving forces for a region. Das Krankenhaus 106: 818-821.

40. Huss WR (1988) A move toward scenario analysis. International Journal of Forecasting 4: 377-388.

41. Albrecht MD, Reichmann H, Töpfer A, Silbermann S, Maertins A (2014) Economic and non-economic benefits of the university hospital and the medica faculty.

42. Töpfer A Silbermann S, Maertins A (2014) Creating values-Opinion of the economical and non-economical effects of Academic Medicine Frankfurt am Main.

43. University Hospital Frankfurt (2014) University hospital contributes more to the federal state than it actually costs.

44. Rippegather J (2014) University hospital creates value-Opinion about the economic importance oft he Academic Medicine Frankfurt am Main. Frankfurter Rundschau.

45. http://www.aerzteblatt.de/nachrichten/59089/Uniklinik-Frankfurt-bringt-mehrein-als-sie-kostet-aber-Oekonomie-ist-nicht-alles.

46. http://www.bild.de/regional/frankfurt/studie-uniklinikum-bringt-mehr-ein-alses-36411660.bild.html

47. http://www.landtag-bw.de/WP15/Drucksachen/4000/15_4523_d.pdf

48. http://www.landtag-bw.de/files/live/sites/LTBW/files/dokumente/WP15/ $\mathrm{Plp} / 150078$ 10102013.pdf

49. Kopietz T (2013) Opinion names figures of value adding of the UMG-Opinion: University Medicine is engine of the economy.

50. Brünjes A (2013) Economic importance of the University Medicine Göttingen Göttinger Tageblatt. 